\title{
Effects of Cardiac Massage and $\beta$-Blocker Pretreatment on the Success Rate of Cardiopulmonary Resuscitation Assessed by the Canine Ischemia/Reperfusion-Induced Ventricular Fibrillation Model
}

\author{
Takeshi Wada, MD, PhD; Mihoko Hagiwara-Nagasawa, PhD; Ryuichi Kambayashi; \\ Ai Goto; Koki Chiba, MD, PhD; Yoshio Nunoi, MD; Hiroko Izumi-Nakaseko, PhD; \\ Tadashi Koga, PhD; Akio Matsumoto, MD, PhD; Yuji Nakazato, MD, PhD; \\ Keith G. Lurie, MD; Atsushi Sugiyama, MD, PhD
}

\begin{abstract}
Background: Effects of rapid electrical defibrillation and $\beta$-blockade on coronary ischemia/reperfusion-induced ventricular fibrillation (VF) during cardiopulmonary resuscitation (CPR) remain unknown.

Methods and Results: After induction of VF by $30 \mathrm{~min}$ of ischemia followed by reperfusion, animals were treated with defibrillation alone (Group A, $n=13$ ), 2 min of open-chest cardiac massage followed by defibrillation (Group $B, n=11$ ), or the same therapy to Group $B$ with propranolol (1 mg/kg, i.v.) treatment before ischemia/reperfusion (Group $C, n=11$ ). If return of spontaneous circulation (ROSC) was not attained, each therapy was repeated $\leq 3$ times (Set-1). When ROSC was not obtained within Set-1, cardiac massage was applied to all animals followed by defibrillation, which was repeated $\leq 3$ times (Set-2). ROSC after Set-1 was $8 \%$ in Group A, $82 \%$ in Group B and $82 \%$ in Group C, whereas that after Set-2 was 62\% in Group A, 100\% in Group B and 82\% in Group C. Each animal with ROSC in Groups A ( $n=8)$ and B ( $n=11)$ showed sinus rhythm, whereas those in Group C ( $n=9)$ had sinus rhythm ( $n=5)$, atrial fibrillation $(n=1)$, accelerated idioventricular rhythm $(n=2)$ and atrioventricular block $(n=1)$. Post ROSC heart rate and mean arterial pressure were significantly lower in Group C.
\end{abstract}

Conclusions: Cardiac massage increased the likelihood of ROSC vs. rapid defibrillation, but $\beta$-blocker pretreatment may worsen hemodynamics and electrical stability after ROSC.

Key Words: Beta-blocker pretreatment; Cardiopulmonary resuscitation; Ischemia/reperfusion-induced ventricular fibrillation; Rapid defibrillation; ROSC rate

$\mathbf{V}$ entricular fibrillation (VF) is a major cause of sudden cardiac death worldwide. ${ }^{1-3}$ American Heart Association (AHA) guidelines for cardiopulmonary resuscitation (CPR) and emergency cardiovascular care recommend standard CPR for improving the success rate of return of spontaneous circulation (ROSC) and neurological outcomes. ${ }^{4}$ In support of this approach for the treatment of out-of-hospital cardiac arrest, a randomized controlled trial showed that 3 min of closed-chest conventional CPR prior to defibrillation in patients with untreated cardiac arrest for $\geq 5 \mathrm{~min}$ improved ROSC rates compared with rapid defibrillation alone. ${ }^{5}$ It is also well established that implantable cardioverter defibrillators, which provide defibrillation in $<15-20$ s after the onset of VF, are highly effective for terminating VF.6,7 However, information regarding the optimal way to manage an out-of-hospital cardiac arrest with CPR and defibrillation in the interval between collapse and $5 \mathrm{~min}$ after collapse remains elusive.

This question regarding whether to perform CPR first or shock first is further complicated by the fact that the initial out-of-hospital cardiac arrest rhythm is not necessarily VF, but often commonly pulseless electrical activity (PEA). ${ }^{8}$ Survival rates when PEA is the first recorded rhythm are lower compared with VF. ${ }^{\mathbf{8}}{ }^{9}$ In this regard, there have been

Received August 26, 2020; revised manuscript received February 10, 2021; accepted February 15, 2021; J-STAGE Advance Publication released online March 25, 2021 Time for primary review: 27 days

Department of Pharmacology (T.W., M.H.-N., R.K., A.G., K.C., Y.N., H.I.-N., T.K., A.S.), Department of Aging Pharmacology (A.M., A.S.), Faculty of Medicine, Toho University, Tokyo; Department of Cardiology, Juntendo University Urayasu Hospital, Chiba (T.W., Y.N.), Japan; Department of Emergency Medicine, University of Minnesota Medical School, Minneapolis, MN (K.G.L.), USA; and Yamanashi Research Center of Clinical Pharmacology, University of Yamanashi, Yamanashi (A.S.), Japan

Mailing address: Atsushi Sugiyama, MD, PhD, Department of Pharmacology, Faculty of Medicine, Toho University, 5-21-16 Omori-nishi, Ota-ku, Tokyo 143-8540, Japan. E-mail: atsushi.sugiyama@med.toho-u.ac.jp

All rights are reserved to the Japanese Circulation Society. For permissions, please e-mail: cj@j-circ.or.jp

ISSN-1346-9843 


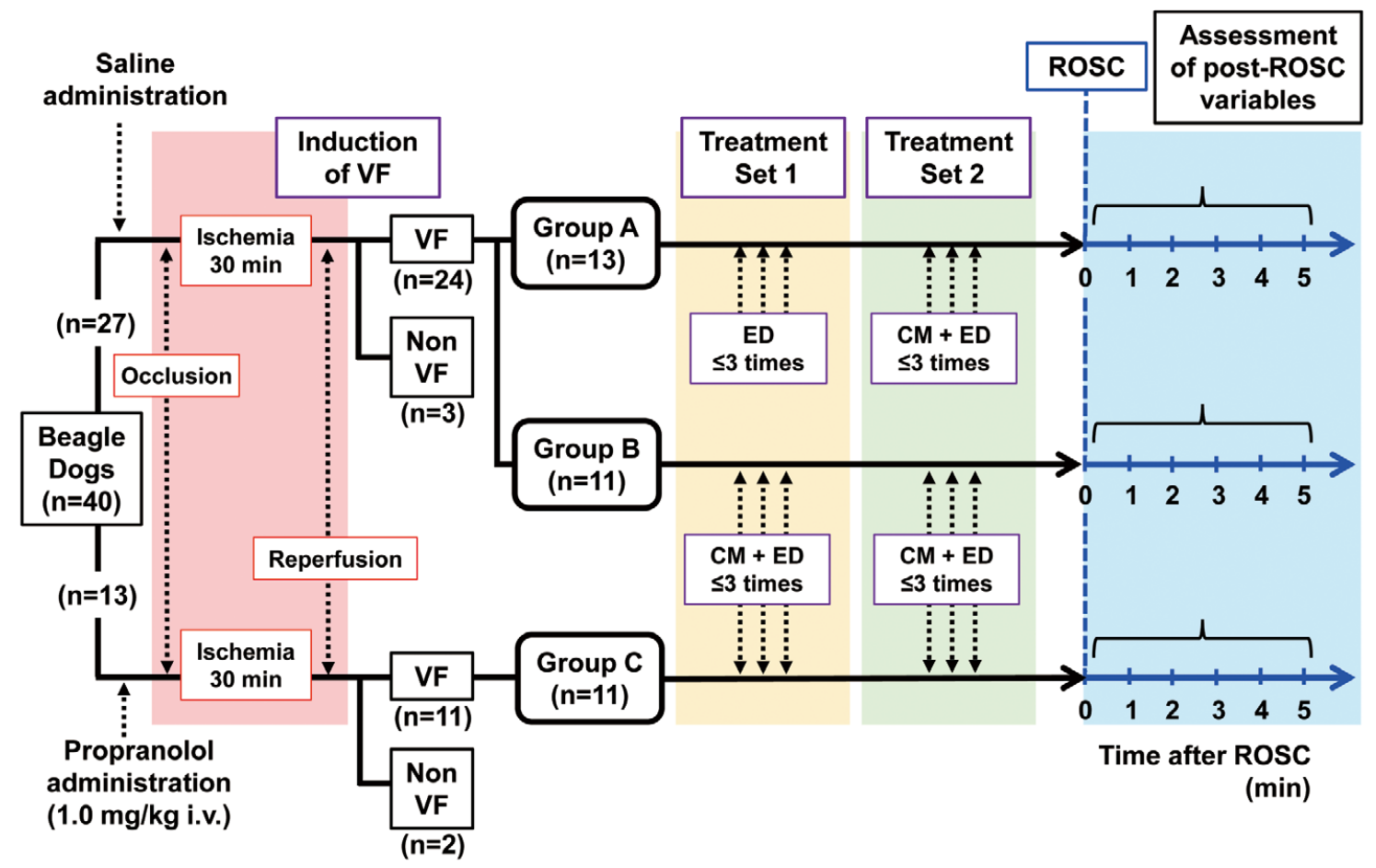

Figure 1. Schematic representation of study protocol. CM, open-chest cardiac massage; ED, electrical defibrillation; ROSC, return of spontaneous circulation; VF, ventricular fibrillation.

a limited number of studies showing that treatment with $\beta$-adrenergic blockers may improve outcomes in cardiac arrest. ${ }^{2}$ Beta-blockers are known to decrease the risk of cardiogenic shock, VF and acute heart failure, ${ }^{10,11}$ and play crucial roles as secondary prevention after the unstable angina pectoris and myocardial infarction. ${ }^{\mathbf{1 0}, \mathbf{1 2}}$ However, in a single-center cohort study, $\beta$-blockers use was associated with a 5-fold increase PEA as the first recorded rhythm compared with VF.13 Thus, information regarding the potential clinical impact of prophylactic $\beta$-blocker treatment on the resuscitation success rate remains limited. In addition, in most of previous experimental studies, ${ }^{2,14}$ pacinginduced VF was used to analyze the efficacy of $\beta$-blockers, which may not necessary reflect the pathophysiology of patients showing sudden cardiac arrest.

To begin to address these clinical questions, we performed translational animal studies to clarify how the timing of delivery of CPR and defibrillation, as well as $\beta$-blocker treatment prior to cardiac arrest, affects outcomes. Since most sudden cardiac deaths are caused by acute coronary syndrome, ${ }^{15,16}$ we utilized a canine ischemia/reperfusioninduced VF model to better mirror the clinical population of patients with out-of-hospital cardiac arrest.

\section{Methods}

All experiments were approved by Yamanashi Research Center of Clinical Pharmacology at the University of Yamanashi (No. 2009-03) and by Toho University Animal Care and User Committee (No. 12-52-152), and performed in accordance with the Guidelines for the Care and Use of
Laboratory Animals of the University of Yamanashi and Toho University.

\section{Animals and Preparations}

Experiments were performed with 40 adult beagle dogs of either sex, weighing approximately $10 \mathrm{~kg}$. These research animals, bred specifically for research, were obtained from Kitayama Labes Co., Ltd. (Nagano, Japan). They were kept in individual cages on a 12-h light (6:00-18:00)-dark (18:00-6:00) cycle. The ventilation provided a total air exchange rate of 10-15 times per hour. The room temperature was maintained at $23 \pm 2^{\circ} \mathrm{C}$, and relative humidity was $50 \pm 30 \%$. Each dog was fed with $200 \mathrm{~g} /$ day of standard diet (CD-5M; CLEA Japan, Inc., Tokyo, Japan), and was allowed free access to tap water.

The dogs were anesthetized with pentobarbital sodium $(30 \mathrm{mg} / \mathrm{kg}$, i.v.) which was supplemented when needed. After intubation with a cuffed endotracheal tube, room air was inhaled with a volume-limited ventilator (SN-480-3; Shinano Manufacturing Co., Ltd., Tokyo, Japan). Tidal volume and respiratory rate were set at $20 \mathrm{~mL} / \mathrm{kg}$ and 15 breaths/min, respectively. Two clinically available catheter sheaths (FAST-CATH ${ }^{\mathrm{TM}}$ 406119; St. Jude Medical, Daig Division, Inc., Minnetonka, MN, USA) were inserted into the aorta through the right femoral artery and into the inferior vena cava through the right femoral vein, respectively. The aortic pressure was measured through a flush line of the catheter sheath placed at the right femoral artery. The surface lead II electrocardiogram was obtained with limb electrodes. The electrocardiogram and aortic pressure were continuously monitored with a polygraph system (RM- 


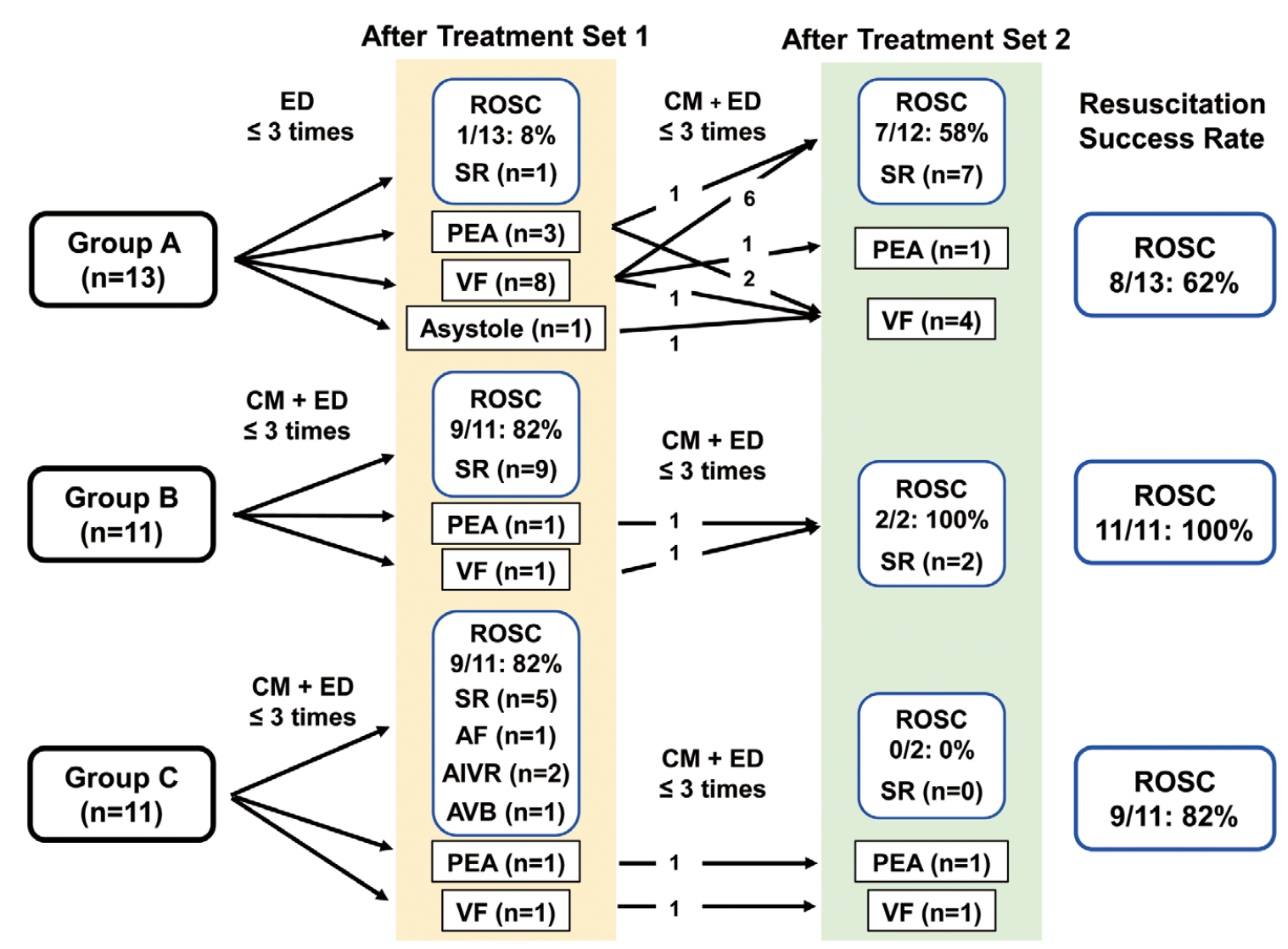

Figure 2. Summary of the effects of study interventions on the defibrillation success and post-shock rhythm. AF, atrial fibrillation; AIVR, accelerated idioventricular rhythm; AVB, atrioventricular block; CM, open-chest cardiac massage; ED, electrical defibrillation; PEA, pulseless electrical activity; ROSC, return of spontaneous circulation; SR, sinus rhythm; VF, ventricular fibrillation.

6000; Nihon Kohden Corporation, Tokyo, Japan).

\section{Induction of VF, Cardiac Massage and Electrical Defibrillation}

The left thoracotomy was performed at the fifth intercostal space. The left anterior descending branch of the coronary artery was identified and occluded for $30 \mathrm{~min}$ at proximal of the first diagonal branch using nylon thread, and then reperfused to induce VF as described previously. ${ }^{17,18}$ Openchest cardiac massage instead of closed-chest one was performed at 80 compressions/min to ensure the consistent cardiac output. CPR was continued for $2 \mathrm{~min}$, of which rate was guided by a metronome in accordance with the AHA guidelines update for CPR and emergency cardiovascular care.,19,20 Electrical defibrillation of $20 \mathrm{~J}$ was applied to the epicardial surface using a hand-held defibrillator paddle (Cardiolife TEC-7721K; Nihon Kohden Corporation). ${ }^{21}$ The cardiac rhythm was assessed for 5-10s after each shock prior to resuming CPR as needed. ${ }^{4}$ ROSC was confirmed by the electrocardiogram and a minimum sustained aortic pressure of $\geq 50 \mathrm{mmHg}$.

\section{Experimental Protocol}

The experimental protocol is summarized in Figure 1. Forty dogs were randomly divided into the vehicle salineadministered group (Groups $\mathrm{A}$ and $\mathrm{B}, \mathrm{n}=27$ ) and $\beta$-blocker propranolol-administered group (Group C, n=13). A volume of $1 \mathrm{~mL} / \mathrm{kg}$ of saline or a dose of $1 \mathrm{mg} / \mathrm{mL} / \mathrm{kg}$ of propranolol was intravenously administered over $10 \mathrm{~min}$ by $30 \mathrm{~min}$ prior to the ischemia/reperfusion. The dose of propranolol was shown to reduce the infarction size induced by the coronary ligation of the left anterior descending branch in a previous mini-swine study. ${ }^{22}$ The aortic pressure and heart rate were continuously recorded, while the animals were ventilated during the experimental period.

Animals that developed VF in the vehicle saline-administered group were randomly divided into Groups A and B. In Group A, defibrillation alone was performed within 30 s after the onset of VF without performing any cardiac massage. In Group B, cardiac massage was started approximately after the onset of VF. After 2 min of cardiac massage, defibrillation was performed. Groups B and C interventions were similar, except that propranolol was used to pretreat animals in Group C. If the ROSC was not attained, each treatment in Groups A to $\mathrm{C}$ was delivered again. This effort was repeated up to total of 3 times as needed (Treatment Set 1). When ROSC was not obtained within Treatment Set 1, cardiac massage was applied to all animals followed by defibrillation, which was repeated in total of $\leq 3$ times (Treatment Set 2). For the purpose of clarity, Treatment Set 1 is defined as the initial treatment assigned to all 3 groups, and Treatment Set 2 is the treat- 

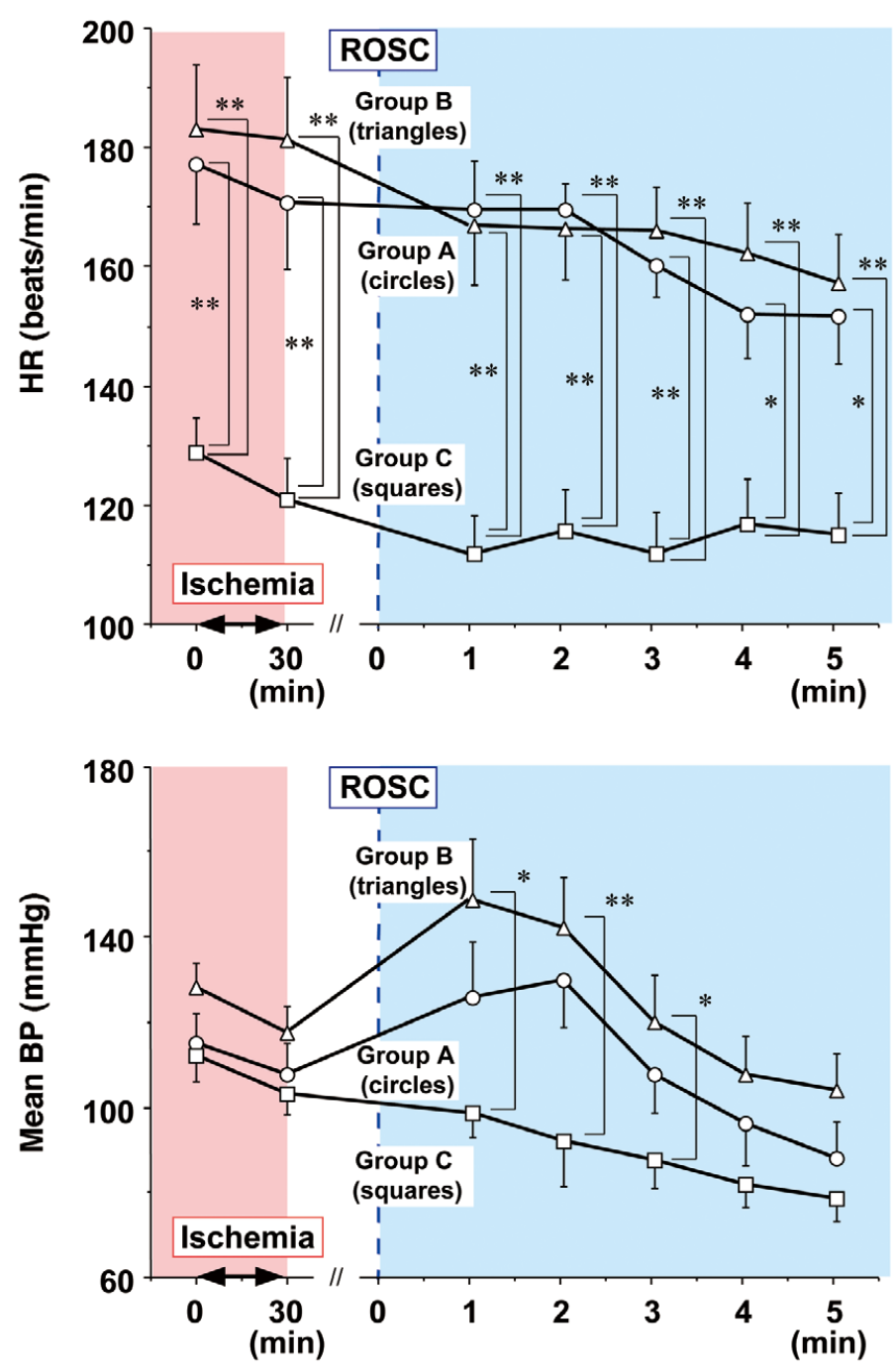

Figure 3. Summary of effects of the study interventions on the heart rate (HR) and mean blood pressure (BP) in the animals with return of spontaneous circulation (ROSC). Data are presented as mean \pm SEM. ${ }^{*} P<0.05$ and ${ }^{* *} P<0.01$ vs. Group $C$. Animals were treated with rapid defibrillation alone (Group A, $n=8$, circles), 2 min of open-chest cardiac massage followed by defibrillation (Group $B, n=11$, triangles) or the same procedure to Group B with propranolol (1 $\mathrm{mg} / \mathrm{kg}$, i.v.) treatment before ischemia/reperfusion (Group C, $n=9$, squares) during Treatment Set 1.

ment received after failure of the initial treatment as part of Treatment Set 1.

In animals with ROSC, the heart rate and aortic pressure were assessed for $5 \mathrm{~min}$. Also, the ventricular premature beats were categorized using the Lown arrhythmia grading system before the reperfusion and at $5 \mathrm{~min}$ after the ROSC. ${ }^{23}$

\section{Drugs}

Propranolol hydrochloride (Inderal ${ }^{\circledR}$; AstraZeneca K.K., Osaka, Japan) and pentobarbital sodium (Tokyo Chemical Industry Co., Ltd., Tokyo, Japan) were purchased and used in this study.

\section{Statistical Analysis}

Data are presented as mean \pm SEM or frequency ( $\%)$. Heart rate and mean blood pressure were analyzed by using a 1-way, repeated-measures analysis of variance followed by Tukey's multiple comparisons test as a post-hoc test for mean value comparison at each time point. Resuscitation success rates between the groups were analyzed by using a Chi-squared test. A P-value $<0.05$ was considered to be statistically significant.

\section{Results}

The coronary reperfusion induced VF in 24 out of 27 saline-administered dogs (Groups A+B: 89\%), and in 11 out of 13 propranolol-administered dogs (Group C: 85\%) (Figure 1). No significant differences were detected in the onset rate of VF between the saline-administered and propranolol-administered dogs.

\section{Effects of Study Interventions on Defibrillation Success and Post-Shock Rhythm}

Figure 2 is a flow chart showing the defibrillation shock success rate in each study group and the resulting recorded heart rhythm. The total number of animals showing ROSC after Treatment Set 1 was 1 out of $13(8 \%)$ in Group A, 9 out of $11(82 \%)$ in Group B and 9 out of $11(82 \%)$ in Group $\mathrm{C}(\mathrm{P}<0.05)$. After Treatment Set 2, ROSC was achieved in 7 out of $12(58 \%)$ in Group A, 2 out of $2(100 \%)$ in Group $\mathrm{B}$ and 0 out of $2(0 \%)$ in Group C. The overall ROSC rate was $62 \%$ in Group A, 100\% in Group B and $82 \%$ in Group 


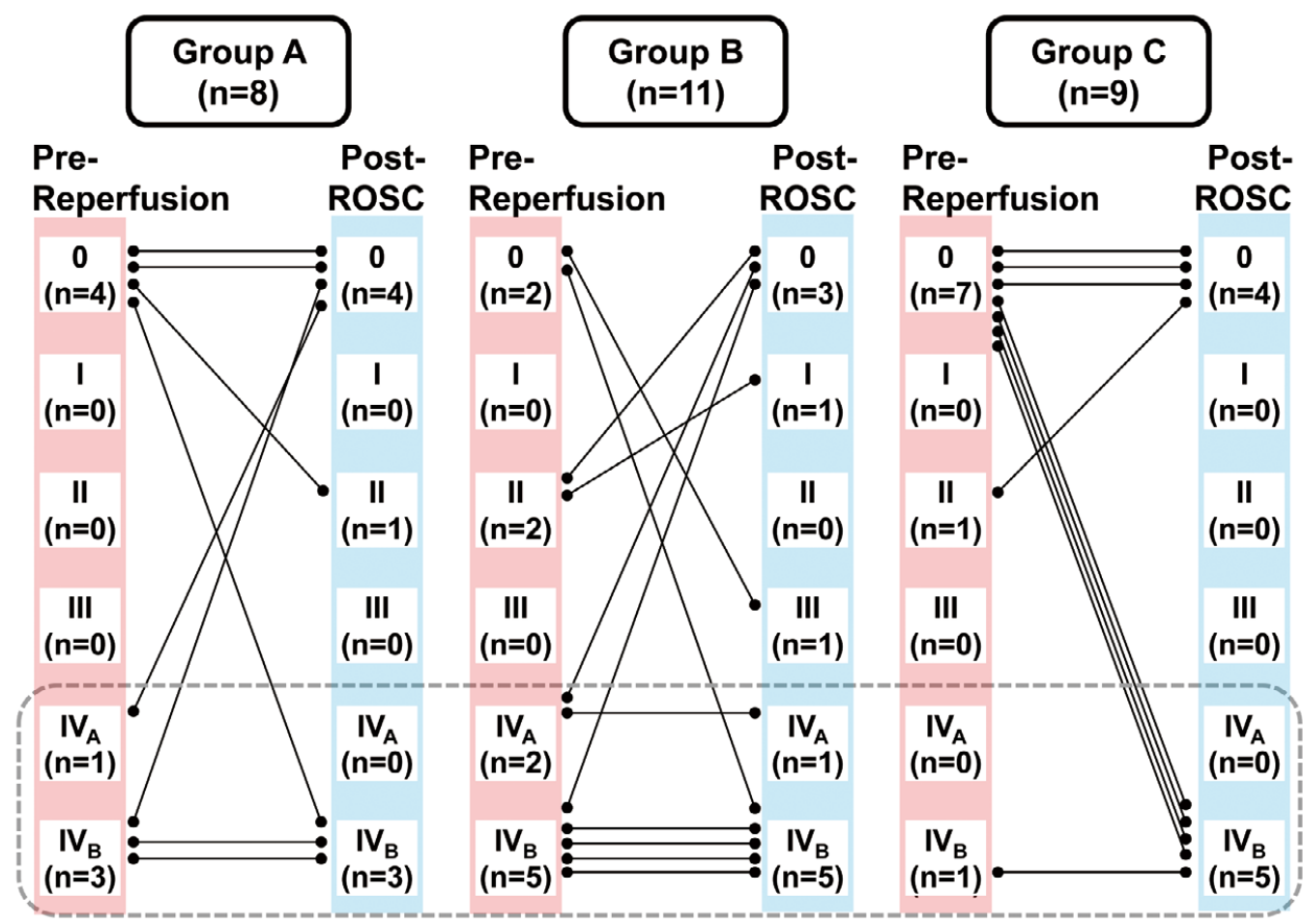

Figure 4. Summary of effects of the study interventions on severity of the ventricular premature beats judged by the Lown arrhythmia grading system in the animals with return of spontaneous circulation (ROSC). Animals were treated with rapid defibrillation alone (Group A, n=8), 2 min of open-chest cardiac massage followed by defibrillation (Group B, $n=11$ ) or the same therapy to Group B with propranolol (1 mg/kg, i.v.) treatment before ischemia/reperfusion (Group C, $\mathrm{n}=9$ ) during Treatment Set 1.

C. Sinus rhythm was observed in all Group A and B dogs with the ROSC after defibrillation. The post-shock rhythms in Group C animals with ROSC were sinus rhythm $(n=5)$, atrial fibrillation $(n=1)$, accelerated idioventricular rhythm $(n=2)$ and complete atrioventricular block $(n=1)$.

\section{Effects of Study Interventions on Hemodynamics}

The time courses of the heart rate and mean blood pressure in animals that obtained ROSC are summarized in Figure 3. The pre-ischemic control values of the heart rate were $177 \pm 10,183 \pm 11$ and $129 \pm 6$ beats $/ \mathrm{min}$, whereas those of mean blood pressure were $115 \pm 7,128 \pm 6$ and $112 \pm 6 \mathrm{mmHg}$ in Groups A, B and C, respectively. The heart rate was significantly higher in Groups A and B than that in Group $\mathrm{C}$ through the whole experimental period. In contrast, the mean blood pressure in Group B was significantly higher for $1-3 \mathrm{~min}$ after the ROSC than that in Group C.

\section{Effects of Study Interventions on the Severity of the Ventricular Premature Beats}

The severity of the ventricular premature beats was compared between the pre-reperfusion period and $5 \mathrm{~min}$ after the ROSC by using the Lown arrhythmia grading system as summarized in Figure 4. The number of dogs showing the arrhythmia grade $\geq$ IV over the total number of ROSC at the pre-reperfusion period and $5 \mathrm{~min}$ after the ROSC was $4 / 8(50 \%)$ and $3 / 8(38 \%)$ in Group A, 7/11 (64\%) and $6 / 11(55 \%)$ in Group B, and $1 / 9(11 \%)$ and 5/9 (56\%) in Group C, respectively. The number of animals showing the arrhythmia grade $\geq \mathrm{IV}$ at the pre-reperfusion period was the lowest in Group C. However, at 5 min after the ROSC, this number slightly decreased in Groups A and B, but markedly increased in Group C compared with that at the pre-reperfusion period.

\section{Discussion}

Patients who present with VF as the first recorded rhythm after cardiac arrest are known to have the highest likelihood of survival. ${ }^{8}$ However, treatment of VF, which would be most commonly caused by ischemia/reperfusion, ${ }^{24}$ remains controversial. For example, despite the many thousands of patients in North American clinical trials, it is unknown whether CPR should be delivered prior to defibrillation for patients with VF for $<5$ min. ${ }^{25,26}$ In addition, it is unknown how the use of $\beta$-blockers in patients prior to developing ischemia/reperfusion VF may alter their outcome. ${ }^{10,11,13}$ These knowledge gaps contribute to the high mortality rates associated with cardiac arrest in patients with VF. Results from this current canine study help to address 2 important issues: should CPR be performed before electrical defibrillation and does $\beta$-blocker pretreatment improve outcomes.

\section{Effects of Rapid Defibrillation and Standard CPR on the Outcome of Resuscitation}

Resuscitation success rate after the rapid electrical defibrillation first without cardiac massage (Group A) was mark- 
edly lower compared with that after cardiac massage followed by shock (Group B). Namely, in Treatment Set 1, as little as $2 \mathrm{~min}$ of cardiac massage before defibrillation increased the defibrillation efficacy $>10$-fold (from $8 \%$ in Group A to $82 \%$ in Group B). The 2 min of cardiac massage followed by defibrillation in Treatment Set 2 increased an overall ROSC rate to $62 \%$ in Group A vs. $100 \%$ in Group B. These results confirm the work of Wik et al, ${ }^{5}$ which indicated the importance of cardiac massage to provide some circulation before defibrillation. There are multiple theoretical reasons why this is important; in effect, cardiac massage would pump out some toxic and arrhythmogenic substances in the ischemic region like lactate and ambient myocardial potassium in addition to delivering oxygen metabolic requirements. ${ }^{5,6}$ Though such mechanisms remain somewhat speculative, the current results definitively confirm the importance of circulation with cardiac massage before defibrillation to improve defibrillation efficacy.

\section{Effects of $\beta$-Blocker Pretreatment on the Outcome of Resuscitation}

Despite the potential benefits of $\beta$-blocker therapy in patients not in cardiac arrest, ${ }^{\mathbf{1 0}-12}$ results from the current study suggest that $\beta$-blockers may not be protective in the instance of VF. Namely, ROSC rates were equivalent or lower in the propranolol-pretreated group (Group C), and its post ROSC blood pressure and heart rate were lower. Importantly, $44 \%$ (4 out of 9 animals) of the post-ROSC rhythms were abnormal in Group C, whereas in Groups A and $\mathrm{B}$, normal sinus rhythm was attained in all of the animals that were not pretreated with propranolol. Although propranolol suppressed the number of ischemiainduced arrhythmias of a Lown grade $\geq \mathrm{IV}$ at pre-reperfusion, it did not reduce the incidence of reperfusion-induced VF. Moreover, in the propranolol-pretreated post-ROSC survivors, the number of arrhythmias of a Lown grade $\geq \mathrm{IV}$ was higher compared with that of pre-reperfusion period, as shown in Figure 4. In addition, they manifested the post-ROSC hemodynamic and electrical instability over time (Group C) vs. the no-propranolol controls (Groups A and B). Given that propranolol blocks the hypotensioninduced, reflex-mediated increase of sympathetic tone on the heart, it is no wonder that propranolol suppressed the sinus nodal and/or atrioventricular function, increasing the cardiac rhythm other than sinus one. Moreover, cardiac systolic function can be directly and/or indirectly suppressed by $\beta$-blockers, particularly in the ROSC heart, which may deteriorate hypotension leading to circulatory failure. ${ }^{14}$ Thus, pretreatment with a therapeutic dose of propranolol did not protect the animals from ischemia/reperfusion cardiac arrest.

\section{Phenotype of PEA}

PEA refers to cardiac arrest in which the electrocardiogram shows the heart rhythm that does not produce a pulse, and it was reported to be initially found in $32 \%$ of subjects in cardiac arrest. ${ }^{27}$ In this study, the total number of animals showing PEA after Treatment Set 1 was 3 out of $13(23 \%)$ in Group A, 1 out of $11(9 \%)$ in Group B and 1 out of $11(9 \%)$ in Group C. After Treatment Set 2, 2 out of 4 animals showing PEA in Groups A and B were converted into sinus rhythm, and the other 2 animals showed VF, whereas 1 animal showing PEA in Group C remained unchanged. These findings suggest that cardiac massage may have some potential to convert PEA into shockable rhythm, including VF, in the absence of $\beta$-blocker pretreatment, possibly through oxygen delivery into the ischemic myocardium as well as washout of deleterious metabolic factors that have accumulated during ischemia. It should be also noted that such conversion of PEA into shockable rhythm was not attained in the animals in Group $C$ with $\beta$-blocker pretreatment, indirectly suggesting that adrenergic regulation on the heart might be at least, in part, associated with the conversion process, which needs to be elucidated.

\section{Study Limitations}

The present study may have several limitations. First, we performed current experiments using the anesthetized intact beagle dogs. Although the canine hearts may possess similar cardiac electrophysiological characteristics to those in humans, ${ }^{\mathbf{2 8}}$ there are some differences in the anatomy of coronary arteries between dogs and humans including collateral networks. The anatomical difference along with the anesthetic condition might have influenced the onset rate of ischemia/reperfusion-induced VF, as well as the resuscitation success rate. Second, we performed open-chest cardiac massage. Although its mechanism of action may not be the same as that of the closed-chest version, the openchest massage will actually be more effective than the closed-chest version. More importantly, the open-chest version is certainly and commonly used in the operation room in the setting of cardiac surgery. Third, we studied the effects of 2 min of cardiac massage, and did not perform it for shorter or longer periods of time before shock, and so this needs to be elucidated to further confirm the hypothesis. Fourth, we did not biochemically examine the mechanisms why cardiac massage before shock delivery improved the defibrillation efficacy. Fifth, only one dose of propranolol was used in this study, limiting its clinical relevance. Assessment of various doses of propranolol may provide a basic understanding to further investigate the utility and limitation of $\beta$-blockers for clinical cardiac emergency. Moreover, another exploratory study is now planning to elucidate which level of $\beta$-blockade may be optimal for remedying the ROSC heart. Finally, another series of projects is now being conducted to compare the difference of ROSC rate with defibrillation first or massage first using animals with untreated cardiac arrest for $\geq 5 \mathrm{~min}$, because cardiac massage and defibrillation together would give a better outcome than defibrillation alone in increasing the ROSC rate according to the latest AHA guideline of resuscitation. ${ }^{29}$

\section{Conclusions}

In this animal model of ischemia/reperfusion-induced VF, CPR before shock, but not pre-treatment with propranolol, significantly increased the likelihood of ROSC vs. rapid defibrillation alone. Beta-blocker pretreatment did not reduce the onset of ischemia/reperfusion-induced VF and may worsen hemodynamics and electrical stability after ROSC.

\section{Acknowledgments}

The authors thank Mrs. Yuri Ichikawa for her technical assistance.

\section{Sources of Funding}

This study was supported, in part, by research grants from JSPS KAKENHI (grant number 17K17068 [to T.W.], 19K16505 [to M.H.-N.] and 20K16136 [to R.K.]). 


\section{Disclosures}

K.G.L. was a consultant for ZOLL Medical and Minnesota Resuscitation Solutions. The other authors declare no conflicts of interest.

\section{IRB Information}

The present study was approved by Yamanashi Research Center of Clinical Pharmacology at the University of Yamanashi (No. 2009-03) and by the Toho University Animal Care and User Committee (No. 12-52-152).

\section{References}

1. Huang Y, He Q, Yang LJ, Liu GJ, Jones A. Cardiopulmonary resuscitation (CPR) plus delayed defibrillation versus immediate defibrillation for out-of-hospital cardiac arrest. Cochrane Database Syst Rev 2014; 2014: CD009803.

2. de Oliveira FC, Feitosa-Filho GS, Ritt LE. Use of beta-blockers for the treatment of cardiac arrest due to ventricular fibrillation/ pulseless ventricular tachycardia: A systematic review. Resuscitation 2012; 83: 674-683.

3. Soar J, Donnino MW, Maconochie I, Aickin R, Atkins DL, Andersen LW, et al. 2018 International consensus on cardiopulmonary resuscitation and emergency cardiovascular care Science with treatment recommendations summary. Circulation 2018; 138: e714-e730.

4. Berg RA, Hemphill R, Abella BS, Aufderheide TP, Cave DM, Hazinski MF, et al. Part 5: Adult basic life support: 2010 American Heart Association guidelines for cardiopulmonary resuscitation and emergency cardiovascular care. Circulation 2010; 122: S685-S705.

5. Wik L, Hansen TB, Fylling F, Steen T, Vaagenes P, Auestad BH, et al. Delaying defibrillation to give basic cardiopulmonary resuscitation to patients with out-of-hospital ventricular fibrillation: A randomized trial. JAMA 2003; 289: 1389-1395.

6. Weisfeldt ML, Becker LB. Resuscitation after cardiac arrest: A 3-phase time-sensitive model. JAMA 2002; 288: 3035-3038.

7. Hallstrom AP, Greene HL, Wyse DG, Zipes D, Epstein AE, Domanski MJ, et al; AVID Investigators. Antiarrhythmics versus implantable defibrillators (AVID): Rationale, design, and methods. Am J Cardiol 1995; 75: 470-475.

8. Yokoyama H, Yonemoto N, Yonezawa K, Fuse J, Shimizu N, Hayashi T, et al. Report from the Japanese registry of CPR for in-hospital cardiac arrest (J-RCPR). Circ J 2011; 75: 815-822.

9. Kajino K, Iwami T, Daya M, Nishiuchi T, Hayashi Y, Ikeuchi $\mathrm{H}$, et al. Subsequent ventricular fibrillation and survival in outof-hospital cardiac arrests presenting with PEA or asystole. Resuscitation 2008; 79: 34-40.

10. Park KL, Goldberg RJ, Anderson FA, López-Sendón J, Montalescot G, Brieger D, et al. Beta-blocker use in ST-segment elevation myocardial infarction in the reperfusion era (GRACE). Am J Med 2014; 127: 503-511.

11. Chen ZM, Pan HC, Chen YP, Peto R, Collins R, Jiang LX, et al. Early intravenous then oral metoprolol in 45,852 patients with acute myocardial infarction: Randomised placebo-controlled trial. Lancet 2005; 366: 1622-1632.

12. Anderson JL, Adams CD, Antman EM, Bridges CR, Califf RM, Casey DE Jr, et al. ACC/AHA 2007 guidelines for the management of patients with unstable angina/non-ST-Elevation myocardial infarction: A report of the American College of Cardiology/ American Heart Association Task Force on Practice Guidelines (Writing Committee to Revise the 2002 Guidelines for the Management of Patients With Unstable Angina/Non-ST-Elevation Myocardial Infarction) developed in collaboration with the American College of Emergency Physicians, the Society for Cardiovascular Angiography and Interventions, and the Society of Thoracic Surgeons endorsed by the American Association of
Cardiovascular and Pulmonary Rehabilitation and the Society for Academic Emergency Medicine. J Am Coll Cardiol 2007; 50: e1-e157.

13. Youngquist ST, Kaji AH, Niemann JT. Beta-blocker use and the changing epidemiology of out-of-hospital cardiac arrest rhythms. Resuscitation 2008; 76: 376-380.

14. Bourque D, Daoust R, Huard V, Charneux M. $\beta$-Blockers for the treatment of cardiac arrest from ventricular fibrillation? Resuscitation 2007; 75: 434-444.

15. O'Gara PT, Kushner FG, Ascheim DD, Casey DE Jr, Chung MK, de Lemos JA, et al. 2013 ACCF/AHA guideline for the management of ST-elevation myocardial infarction: A report of the American College of Cardiology Foundation/American Heart Association Task Force on Practice Guidelines. J Am Coll Cardiol 2013; 61: e78-e140.

16. Niemann JT, Rosborough JP, Youngquist S, Thomas J, Lewis RJ. Is all ventricular fibrillation the same?: A comparison of ischemically induced with electrically induced ventricular fibrillation in a porcine cardiac arrest and resuscitation model. Crit Care Med 2007; 35: 1356-1361.

17. Naito M, Michelson EL, Kmetzo JJ, Kaplinsky E, Dreifus LS Failure of antiarrhythmic drugs to prevent experimental reperfusion ventricular fibrillation. Circulation 1981; 63: 70-79.

18. Yamada C, Xue Y, Chino D, Hashimoto K. Effects of KB-R9032, a new $\mathrm{Na}^{+} / \mathrm{H}^{+}$exchange inhibitor, on canine coronary occlusion/ reperfusion-induced ventricular arrhythmias. J Pharmacol Sci 2005; 98: 404-410.

19. Kleinman ME, Brennan EE, Goldberger ZD, Swor RA, Terry M, Bobrow BJ, et al. Part 5: Adult basic life support and cardiopulmonary resuscitation quality: 2015 American Heart Association guidelines update for cardiopulmonary resuscitation and emergency cardiovascular care. Circulation 2015; 132: S414-S435.

20. Dunning J, Fabbri A, Kolh PH, Levine A, Lockowandt U, Mackay J, et al. Guideline for resuscitation in cardiac arrest after cardiac surgery. Eur J Cardiothorac Surg 2009; 36: 3-28.

21. Kerber RE, Carter J, Klein S, Grayzel J, Kennedy J. Open chest defibrillation during cardiac surgery: Energy and current requirements. Am J Cardiol 1980; 46: 393-396.

22. Zhao J, Yang Y, You S, Cui C, Gao R. Carvedilol preserves endothelial junctions and reduces myocardial no-reflow after acute myocardial infarction and reperfusion. Int J Cardiol 2007; 115: $334-341$.

23. Lown B, Wolf M. Approaches to sudden death from coronary heart disease. Circulation 1971; 44: 130-142.

24. Olgin JE, Tomaselli GF, Zipes DP. Ventricular arrhythmias. In: Zipes DP, Mann DL, Libby P, Tomaselli GF, Bonow RO, Braunwald E, editors. Braunwald's heart disease: A textbook of cardiovascular medicine, 7th edn. Philadelphia: Saunders, 2004; $753-771$.

25. Stiell IG, Wells GA, Field B, Spaite DW, Nesbitt LP, De Maio VJ, et al. Advanced cardiac life support in out-of-hospital cardiac arrest. $N$ Engl J Med 2004; 351: 647-656.

26. Stiell IG, Brown SP, Christenson J, Cheskes S, Nichol G, Powell $\mathrm{J}$, et al. What is the role of chest compression depth during outof-hospital cardiac arrest resuscitation? Crit Care Med 2012; 40: $1192-1198$.

27. Keller SP, Halperin HR. Cardiac arrest: The changing incidence of ventricular fibrillation. Curr Treat Options Cardiovasc Med 2015; 17: 392.

28. Sugiyama A. Sensitive and reliable proarrhythmia in vivo animal models for predicting drug-induced torsades de pointes in patients with remodelled hearts. Br J Pharmacol 2008; 154: $1528-1537$.

29. Olasveengen TM, Mancini ME, Perkins GD, Avis S, Brooks S, Castrén M, et al. Adult Basic Life Support Collaborators. Adult Basic Life Support: 2020 International consensus on cardiopulmonary resuscitation and emergency cardiovascular care science with treatment recommendations. Circulation 2020; 142: S41-S91. 